\title{
Notas sobre unhas supostas especificidades semánticas na fala de Cáceres ${ }^{1}$
}

\author{
Xosé Afonso Álvarez PÉREz \\ Centro de Linguística da Universidade de Lisboa \\ xoseafonso.alvarez@gmail.com
}

\begin{abstract}
RESUMO
No noroeste de Cáceres existe unha variedade romance, a fala, de filiación discutida. O recente libro de Costas (2013) agrupa diferentes traballos que defenden a orixe galega, mediante procesos medievais de repoboamento. Un apartado recolle unha selección de palabras cun significado particular nesa variedade, unha listaxe que podería aducirse como proba do carácter singular destas variedades con respecto ás linguas do seu contorno e do seu afastamento con respecto ó portugués. Non obstante, este artigo propón unha análise contrastiva entre esas formas e os materiais dialectais casteláns e portugueses que revela que a situación está lonxe de ser como describe Costas. De feito, case a metade dos significados presentados nesa listaxe como propios da fala están perfectamente documentados no portugués dialectal. Este traballo quere reivindicar a necesidade de ter presentes os materiais dialectais próximos ó Val do Ellas, precaución necesaria para chegar a conclusións rigorosas sobre a orixe da fala.
\end{abstract}

Palabras-chave: Fala, portugués, galego, Cáceres, léxico dialectal, innovación semántica.

[Recibido, abril 2014; aprobado, enero 2015]

Some remarks about alleged semantic specificities in the fala of Cáceres

\begin{abstract}
In the northwest of Cáceres there is a Romance variety with controverted affiliation. The recent book of Costas (2013) gathers several works that defend a Galician origin, explained by medieval processes of repopulation. One section contains a selection of words that have acquired a meaning in that variety; this list could be used as an evidence of the special character of this language with respect to its neighbours and to point out its distance from Portuguese. Nevertheless, this paper proposes a contrastive analysis between those words and Castilian and Portuguese dialectal materials that reveals that the situation is far from Costas' description. In fact, almost half of the meanings that were presented as specificities of the fala are well documented in dialectal Portuguese. This paper aims to claim the need to consider dialectal materials produced close to the Valley of the Ellas, since they are essential to reach rigorous conclusions about the origin of the fala.
\end{abstract}

Keywords: Fala, Portuguese, Galician, Cáceres, dialectal vocabulary, semantic innovation.

\footnotetext{
1 Este traballo foi subsidiado mediante unha axuda de recursos humanos da Fundação para a Ciência e a Tecnologia do goberno portugués (SFRH/BPD/72238/2010).
} 


\section{Introdución: as falas do Val do Ellas}

O Val do Ellas, ou Val de Xálima, está formado por tres concellos do noroeste da provincia de Cáceres: San Martín de Trevejo, Eljas e Valverde del Fresno, segundo a toponimia oficial española, e Sa(n) Martín de Trevellu², As Ellas e Valverdi du Fresno na denominación local. De aí outra denominación, os Tres Lugares. Nese territorio fálase unha variedade lingüística iberorrománica normalmente coñecida como Fala; toda vez que existe unha certa diferenciación interna entre os dialectos falados en cada un dos municipios, é tamén habitual referirse a eles por separado: lagarteiro (As Ellas), mañego (San Martiño) e valverdeiro ou chapurráu (Valverde).

Debido á súa situación fronteiriza e á existencia de enclaves lusófonos en varios lugares de Castela e León e Estremadura, tradicionalmente esas falas foron consideradas dialectos portugueses antigos ou variedades mixtas nacidas do contacto entre castelán e portugués nun contexto fronteirizo. Non obstante, desde o redescubrimento da lingua desa zona hai xa máis de 20 anos, sucedéronse os traballos filolóxicos ou histórico-filolóxicos que se achegan á cuestión da orixe e filiación lingüística destas variedades, con posicións de todo tipo; Gargallo (2007) contén unha síntese de amena lectura.

Posiblemente, a postura máis asentada entre os investigadores é a de considerar as falas do Val do Ellas como un continuador do galego-portugués medieval -Juan M. Carrasco chegou a falar de "terceira póla", cf. Carrasco (1996)- chegado a ese territorio mediante procesos de repoboamento, diferente, por tanto, do portugués dialectal das Beiras. Non obstante, un grupo de investigadores, mormente galegos, matizou que non sería correcto pór ó mesmo nivel o galego, o portugués e as falas do Val do Ellas, senón que realmente estas últimas serían unha continuación do galego (xa non do galego-portugués) medieval, levado ata esas terras por colonos xa no s. XIII.

O maior representante desta postura é o filólogo vigués Xosé-Henrique Costas González, unha das persoas que máis se entregou ó estudo das falas de Xálima e gran dinamizador do territorio, da súa cultura e lingua. En 2013, Costas deu ó prelo o seu libro O valego. As falas de orixe galega do Val do Ellas (Cáceres-Estremadura), que sintetiza dúas décadas de traballo sobre estas variedades. Este libro contén unha sección VII.2.3. dedicada ó léxico que pretende xustificar a afirmación de que "no léxico do valego é onde máis se nota o seu carácter de fala galega arcaica e arraiana, de illa diferente ou sitio distinto rodeado de portugués beirão e castelán aleonesado" (Costas 2013: 176).

A maior parte do capítulo está dedicada á análise de formas lexicais que é suposto seren arcaísmos xa desaparecidos do galego moderno e ó estudo de designacións que, en principio, serían comúns ó galego e ás falas do Val do Ellas, mais non ó castelán ou portugués dialectais; trátase, obviamente, dunha tentativa de mostrar as semellanzas entre as dúas variedades, coa intención de apoiar a postura que sostén a filiación directa entre elas. Fago un exame crítico desta análise dialectal noutro traballo, actualmente en avaliación nunha revista. Outra parte do capítulo de Costas dedícase á exposición de "exemplos de significante galego con significado dialectal valego" (Costas 2013: 188). Será esta a cuestión sobre a que me deteña neste artigo, tal e como detallo na sección vindeira.

\footnotetext{
${ }^{2}$ Polémico topónimo empregado polo concello, co que moitos falantes non se senten identificados, pois prefiren a forma San Martín. Tamén existe un topónimo galeguizado, San Martiño de Trebello.
} 


\section{Obxecto do estudo e metodoloxía}

Costas (2013: 188-193) recolle varias designacións comúns a galego, portugués e Val do Ellas que, ó seu xuízo, desenvolveron un significado derivado específico nas terras de Xálima, ata o punto de que, segundo afirma, para o falante galego o máis sorprendente do léxico da Fala son os cambios de significado que se observan no vocabulario.

No entanto, unha lectura inicial da relación de conceptos exposta no libro mostrou que varios deses significados que era suposto seren específicos do Val do Ellas tamén se documentaban, co mesmo significante, no portugués común ou no portugués dialectal das Beiras. Fíxose necesario, por tanto, un confronto sistemático das formas propostas por Costas, para poder verificar en que grao se pode falar dunha identidade lexical característica do Val do Ellas e ata que punto é realista a afirmación de que esa zona presenta unha imaxe lingüística afastada do portugués, un dos piares sobre os que se asenta a teoría da orixe galega das falas dos Tres Lugares. Este artigo propón, por tanto, unha ollada máis rigorosa e detallada para o léxico do Val do Ellas e presenta as principais fontes dispoñibles para o estudo do portugués dialectal, uns materiais que non sempre son ben coñecidos, e, aínda menos, utilizados, na lingüística galega.

No que respecta ós materiais lexicográficos portugueses, consultei sistematicamente a $24^{\mathrm{a}}$ edición (1939) impresa do dicionario Cândido de Figueiredo (citado de modo abreviado como CF) e, nas súas edicións electrónicas, o Dicionário da Língua Portuguesa da Porto Editora (P.Ed.), o Dicionário Priberam da Língua Portuguesa (Prib.) e mais a $3^{\text {a }}$ edición do Dicionário Eletrônico Houaiss da Língua Portuguesa (Houaiss). No que respecta ás fontes dialectais, os dous piares fundamentais, para alén do corpus de artigos da Revista Lusitana (RL), foron os materiais inéditos do Atlas Linguístico-Etnográfico de Portugal e da Galiza (ALEPG) (Saramago 2006) -a pesar de estar en proceso de edición, os cuestionarios e gravacións están ó dispor dos investigadores interesados no Centro de Linguística da Universidade de Lisboa (CLUL) - e diferentes monografías etnolingüísticas sobre diferentes zonas de Portugal tamén conservadas no $\mathrm{CLUL}^{3}$. Aínda que estes recursos, e outros que tamén se consultaron, proporcionan unha visión aceptable do territorio portugués, non se trata dunha perspectiva exhaustiva, xa que, lamentablemente, queda moito aínda por labrar no campo dos estudos dialectais en Portugal.

\section{Análise do corpus}

\subsection{Significados con correspondencia clara nos dicionarios portugueses ou no portu- gués dialectal}

\section{§1. Agafañar: 'roubar' (significado habitual: 'coller coa garra')}

Costas (2013: 192) acudira a Cândido de Figueiredo para sinalar que este termo está rexistrado en portugués como "voz rexional, co sentido de «agarrar coa gafa»". Descoñezo cal foi a edición do dicionario que manexou o filólogo vigués; en calquera caso, a que consultei eu (24, ano 1939) inclúe unha entrada agafanhar, definida literalmente como "Agarrar com

\footnotetext{
${ }^{3}$ A maioría desas monografías xa está integrada no Tesouro do Léxico Patrimonial Galego e Portugués (TLPGP) dirixido por Rosario Álvarez no Instituto da Lingua Galega: http://ilg.usc.es/Tesouro/ (consultado o 24 de marzo de 2014).
} 
a gafa. Empolgar"; e para empolgar, as tres primeiras acepcións que dá ese mesmo dicionario son: "Agarrar. Apoderar-se de. Adquirir com violência ou injustiça". En calquera caso, a consulta doutros dicionarios de referencia (entre eles o da Porto Editora e mais o Houaiss) recupera agafanhar con varias acepcións, entre elas, 'furtar'.

\section{$\S 2$. Argola: 'pendente da orella' (significado habitual: 'aro')}

Este desprazamento semántico que se sinala no Val do Ellas é ben coñecido en portugués, a través da acepción intermedia 'pendente en forma de aro', tamén ben documentada no uso.

Os dicionarios da Porto Editora, da Priberam e o Houaiss inclúen o significado 'pendente en forma de anel' como terceira acepción de argola. Por súa vez, a pregunta 580 do ALEPG, que examina o concepto 'pendente', mostra que varios puntos portugueses responden argola para ese concepto, ás veces como sinónimo perfecto de brinco, ás veces especificando algún matiz diferenciador, que non ten que ser a morfoloxía circular, senón que pode radicar no tamaño; por exemplo, en Folques (Coimbra) as argolas son "brincos grandes".

Este significado innovador tamén está ben presente na zona arraiana, máis alá do Val do Ellas. Maia (1977) documentara argolas en San Martiño e en Valverde, definidas como "arrecadas"4; non obstante, tamén rexistra esa forma, co mesmo significado, en tres localidades do municipio portugués do Sabugal: Aldeia do Bispo, Foios e Lageosa. Tamén se recompilou argola con esa acepción en Cedillo (Vilhena 2000).

\section{§3. Fato: 'enxoval, pertenzas persoais' (significado habitual: 'traxe de festa')}

Esta palabra está documentada nalgunhas fontes lexicográficas portuguesas, aínda que con pouca presenza. O Vocabulario de Bluteau dá referencias do seu uso con este sentido: "§ Fato da casa. Supellex, ctilis. Fem.(sem plural) Cic. Vid. Moveis. Mudar o fato. Supellectilem ex eâ domo, ex qua migrandum aliò exportare (o, avi, atum) Que tem pouco fato. Cui est curta supellex. Horat.". Aparece tamén no Cândido de Figueiredo, con diversas restricións diatópicas e diacrónicas, aínda que cómpre ter presente que ese dicionario non sempre adxudica e administra de modo rigoroso esas etiquetas: "Des. Móveis. T. de Macau e da Índica Port. Bagagem; mobília”; o Priberam elimina eses marcadores, mais o significado que nos interesa ocupa apenas o sétimo lugar entre as acepcións: "Móveis; haveres".

Por contra, no portugués dialectal as referencias son máis abundantes. Citarei dous exemplos de monografías etnolingüísticas da Beira e Alentejo onde fato aparece co valor de 'enxoval'; Carreiro (1948) documéntao en Nisa como "roupa de cama" e Buescu (1961) rexistra en Monsanto o significado "qualquer roupa de uso pessoal ou não".

No que respecta ás linguas veciñas, o valor semántico que indica Costas está perfectamente representado no español hato ("Ropa y otros objetos que alguien tiene para el uso preciso y ordinario", DRAE).

§. Fío: 'colar para as persoas' (significado habitual: 'filamento’)

A forma fio tamén adquiriu ese significado especializado en portugués. A pregunta 581 do ALEPG examina o concepto cordão, isto é o fío metálico que penduran as persoas do pescozo. O atlas rexistra varias respostas do tipo fio en diversos distritos portugueses,

\footnotetext{
4 "Brinco em forma de argola" (Porto Editora).
} 
incluídos a Guarda e Portalegre ${ }^{5}$; como as pezas do vestiario deixaron de preguntarse nas enquisas dos anos noventa, é difícil ofrecer unha visión detallada da súa distribución xeográfica. As monografías dialectais da zona tamén confirman o seu uso na zona fronteiriza máis achegada ó Val do Ellas. Vilhena (2000) documentou a forma en Ferreira. Por súa vez, Reinas (1957) rexistra fio dun e doutro lado da Raia, en Nave de Haver e en La Alamedilla; aínda que non o define, inclúe o termo dentro do campo semántico do vestiario.

\section{§5. Lambón: 'ladrón' (significado habitual: ‘larpeiro')}

Costas (2013: 189n) matiza que o significado secundario pode aparecer esporadicamente en galego, polo que a orixinalidade do Val do Ellas radicaría en que neste territorio a designación lambón só se aplicaría ó ladrón. Non obstante, Rey Yelmo (1999) parece contradicir esa afirmación, pois o seu vocabulario mañego contén a entrada lambón(-ona) "glotón".

O portugués da Beira coñece lambão normalmente co significado 'indolente, preguizoso'. Non obstante, o valor atribuído ó Val do Ellas non é descoñecido en Portugal, como se constata na entrada lamber de CF, que ten "apanhar, furtar" entre as acepcións para ese termo.

§6. Liña: 'fío para coser' (significado habitual: 'liña, fío de pesca')

En primeiro lugar, cómpre matizar que, aínda que Costas (2013: 189) inclúe esta forma dentro dunha relación de falsos amigos entre o galego e o valego, realmente a acepción supostamente particular do Val de Xálima non é descoñecida en Galicia. Así o refire, por exemplo, a sétima acepción de liña no DRAG, "Febra de fío, seda etc., que se utiliza para coser", e así aparece na maioría das obras incluídas no Dicionario de dicionarios (Santamarina 2006), desde Sobreira e Payzal ata García (1985); algún dicionario menciona, incluso, un testemuño galego dun coñecido tópico da paremioloxía peninsular: "Jastre das Bahiñas que cose de valde é mais pon as liñas”.

No que respecta ó portugués, o significado 'fío de coser' é totalmente cotián nesa lingua, como se pode comprobar coa consulta da entrada linha en calquera dicionario de uso, tal como "1. Fio para coser" (Prib.). De feito, é a única resposta documentada na pregunta do ALEPG que estuda ese concepto $\left(\mathrm{n}^{\mathrm{o}} 1659\right)$. Non abunda nas teses dialectais, posiblemente por coincidir en forma e significado co estándar, mais hai algunha referencia do seu uso con este valor na zona fronteiriza, por exemplo en Ferreira e Cedillo (Vilhena 2000).

§7. Mela, melar, melao: 'corte, necha, nicada ou fanada que ten ou se lle fai a un obxecto'

Familia léxica de etimoloxía incerta, na época medieval en galego significaba fanado, nicado etc. Do portugués medieval non conservamos rexistros, pero no actual é corte na folla dunha ferramenta, oco, claro etc. En galego moderno os dicionaristas recollen melar con tres significados: a) endozar con mel: b) variante de merar c) rachar, fender o gume dun instrumento cortante. Neste último sentido só o temos en Valladares (1884) e Carré (1928). No valego do Ellas é un corte, necha, nicada ou fanada que ten ou se lle fai a un obxecto. (Costas 2013: 193).

\footnotetext{
${ }^{5}$ Neste último distrito, e a media ducia de quilómetros da fronteira con Cáceres, xa a rexistrara Baptista (1967) na Escusa (Marvão).
} 
Semella, por tanto, que a orixinalidade do Val do Ellas radica no feito de que mela/melar pode aplicarse a un corte en calquera obxecto, e non só no fío dos instrumentos cortantes. Poderíase observar, no entanto, que non consta tal ampliación de significado na recolla de vocabulario mañego de Rey Yelmo (1999): "Mela: Mella, rotura o hendedura en el filo de una arma o herramienta"; agora ben, isto non exclúe que haxa casos particulares, e tampouco se pode desbotar a idea de que Rey Yelmo se deixase levar na definición pola textualidade do DRAE, que segue bastante fielmente.

$\mathrm{O}$ feito é que, aínda que esa familia se refira preferentemente ós instrumentos cortantes, tanto en galego coma en portugués hai testemuños de uso con outros obxectos. O suplemento do dicionario de Valladares (García Ares 2000, apud Santamarina 2006) contén unha entrada melar "Mellar, rajar o descantillar una cosa hendiéndola o sacándole una porción corta", nun sentido semellante ó verbo portugués melar, que aparece definido dunha forma xenérica "fazer mossas em" (Prib.). Do mesmo modo, aínda que algúns dicionarios portugueses restrinxen mela ó campo dos obxectos cortantes, CF opta por unha definición máis xenérica que non exclúe posibilidades alternativas: "Falha, mossa, especialmente nos instrumentos de corte". O mesmo acontece coa primeira acepción de mella no DRAE, restrinxida no inicio e máis aberta despois: "1. f. Rotura o hendidura en el filo de un arma o herramienta, o en el borde o en cualquier ángulo saliente de otro objeto, por un golpe o por otra causa".

$\S 8$. Vieiro: 'gabia, escavación lineal realizada polo home' (significado habitual: camiño estreito)

Aínda que os rexistros son escasos, o portugués dialectal non descoñece a forma vieiro dentro deste arco semántico, cuberto en gran parte pola forma do estándar vala. Carvalho (1970) rexistra en Sátão (municipio do distrito de Viseu) a forma vieiro, que define como "guieiro", que, por súa vez, ten entre as súas acepcións habituais unha que se aproxima moito ó concepto que aquí nos ocupa: "rego por onde se conduz a água de rega" (P.Ed.). En Santa Vitória do Ameixial, no concello alentexano de Estremoz, tamén se documenta vieiro "Marca, divisoria de propriedades" (RL XIX, 323). As poucas veces que vieiro aparece nos dicionarios portugueses é para remitir a veeiro, un derivado de veio (" 1 . faixa comprida e estreita que, num terreno, madeira ou rocha, se distingue pela sua cor diferente ou pela natureza da sua substância [...] 4. fio de água corrente; riacho; veia", P.Ed.).

En calquera caso, hai un problema metodolóxico semellante ó referido en $\S 6$. Costas (2013: 188-189) clasifica esta palabra dentro da tipoloxía "significante galego con significado dialectal valego". Porén, Rivas Quintas (2001, apud Santamarina 2006) documenta en galego a forma vieiro con significados que aquí nos interesan: "Zanja profunda que se hace cuando se planta una viña de nuevo; División y paso entre canteros (nabeiras) de una huerta; reguera que lleva el agua". Por tanto, semella dubidoso que se poida falar dunha especificidade semántica do Val do Ellas.

§9. Xaneiro/a: 'primeira cría nacida no ano e as crías ou froitos que veñen en xaneiro' (significado habitual: 'primeiro mes do ano')

De novo, esta translación de significado é normal en portugués, só que esta lingua adoita empregar a forma diminutiva: janeirinho/a "1. Próprio do mês de Janeiro. 2. Que nasce ou se cria em Janeiro" (Prib.); esta coexiste, por suposto, con formas derivadas como janeireiro "que nasce em janeiro; que só floresce ou se cria nesse mês" (Houaiss). A partir dese uso 
adxectivo aparecen tamén substantivos como janeiras "Nome vulgar de certas plantas que florescem em Janeiro" (Prib.) ou janeirinha, a belota que nace no primeiro mes do ano (ALEPG, pregunta 1079.3). En Monsanto, unha freguesía practicamente lindeira co Val do Ellas, Buescu (1961) documenta janeiro/a como adxectivo para as reses nacidas en decembro ou xaneiro. No que respecta ó galego, Rivas Quintas (2001, apud Santamarina 2006) tamén rexistra xaneiro/a como adxectivo, só que cun carácter máis xeral ("propio del mes de enero") e a partir do dicionario de Carré (1951) tamén se documenta xaneiriño con ese mesmo significado.

A innovación atribuída ós Tres Lugares non é, por tanto, orixinal; non obstante, seguramente a perda de xaneiro como denominación do mes (en favor do castelanismo eneru) contribuíu a dar destaque a este particular valor semántico.

§10. Xeira: 'campo ou leira que se traballa nun día' (significado habitual: 'xornada de traballo')

Costas (2013: 188) enumera esta forma dentro dun "inventario amplísimo de formas comúns co galego (e co portugués) que neste val van coller un significado derivado diferente", xa que en Xálima pasou de significar 'xornada de traballo' a denominar o 'campo ou leira que se traballa nun día'.

Habería que matizar, en primeiro lugar, que non semella que se trate da adquisición dun significado realmente diferente, senón dun proceso metonímico bastante esperable. En calquera caso, a orixinalidade do Val do Ellas non é tal cando se olla para os dominios lingüísticos veciños. A acepción principal de jeira nos dicionarios portugueses resulta ser, precisamente, "terreno que uma junta de bois pode lavrar num dia" (P.Ed.). Tanto ese valor coma o de 'día de traballo' están presentes na pregunta 2036 do ALEPG, que ten jeira como resposta hexemónica.

No portugués da Beira máis próximo xeograficamente ó Val do Ellas tamén están presentes os dous significados, se ben que non todas as fontes o reflictan. Fernandes (1965) documenta as dúas acepcións en Aldeia Velha e poboacións veciñas, mentres que Braga (1971) e Reinas (1957) só rexistran en Nave de Haver, Poço Velho Quadrazais e La Alamedilla o de 'traballo realizado nun día'. Por súa vez, o blogue O falar de Riba Côa non especifica localidades concretas, mais si que deixa constancia do uso das dúas acepcións: "JEIRA - lavra de um dia (cerca de meio hectare); trabalho do lavrador de sol a sol. Espaço de terra lavrada por uma junta de vacas durante a jorna (Duardo Neves). Salário devido a um trabalhador por cada dia de trabalho (Júlio António Borges)"”.

\subsection{Significados con correspondencia nas comunidades lusófonas de España e terras veciñas}

§11. Cileiro: 'Dormitorio pequeno' (significado habitual: 'almacén, despensa')

Esta deriva semántica, que Costas (2013: 188) explica polo feito de que os criados e xornaleiros acostumaban durmir en almacéns e despensas, non é exclusiva dos Tres Lugares.

\footnotetext{
${ }^{6} \mathrm{http}: / /$ capeiaarraiana.pt/2013/10/26/o-falar-de-riba-coa-o-lexico-73/ (consultado o 6 de marzo de 2014).
} 
En Ferreira documéntase cileru coa definición "quarto de dormir independente" (Vilhena 2000). Algo máis preto do Val do Ellas, a uns $40 \mathrm{~km}$, Cummins (1974: §71a), cando describe a casa tradicional de Coria (Cáceres), sinala que o cuarto de durmir chámase sala se hai xanela e cillero se non a hai. Habería que investigar con algo máis de vagar que acontece no galego, xa que, entre outras moitas acepcións, a entrada celeiro no dicionario de Eladio Rodríguez tamén menciona o valor de residencia: "Pequeña casa terrena en que vive una persona pobre: cileiro, zoleiro, zuleiro".

\section{§12. Fogar: 'cociña (cuarto e fogóns)' (significado habitual: 'casa, vivenda')}

O dicionario da Porto Editora inclúe unha entrada fogar, cunha segunda acepción interesante para este comentario: "casa habitada; fogo; casal". No entanto, trátase dunha forma anticuada no portugués actual, onde entrou posiblemente por vía do castelán, sen chegar a suplantar nin a lar nin a fogão. De feito, se acudirmos ó DRAE, veremos que a primeira acepción de hogar aínda hoxe é "Sitio donde se hace la lumbre en las cocinas, chimeneas, hornos de fundición, etc.”, na liña do significado sinalado por Costas para o Val do Ellas.

Nas fontes dialectais de Portugal consultadas non encontro rexistros de fogar. Porén, o exame das respostas á pregunta 1028 do ALEP ("hogar (sitio donde se enciende el fuego)") rexistra a forma fogar en dúas comunidades lusófonas en territorio español, La Codosera e Valencia de Alcántara, mentres que cocina é a resposta que se documenta noutras localidades da zona (Cheles, Olivenza e Valencia de Mombuey); en Valverde del Fresno rexístrase piedra de la chimenea neses materiais, pero Maia (1977) anotara cociña como resposta a ese concepto.

\subsection{Formas documentadas no castelán ou no portugués cun significado moi próximo}

\section{§13. Cociña: 'cocido' (significado habitual: 'lugar onde se cociña')}

A definición sinonímica indicada por Costas (2013: 189) é un pouco imprecisa, xa que non se indica se, para alén do que coñecemos normalmente como cocido ("Comida constituída fundamentalmente de carne de porco, vaca e galiña, touciño, chourizos, fabas, patacas e verduras, cocido todo en auga", DRAG), a forma cociña designa nos Tres Lugares algunha outra especialidade culinaria, como acontece con frecuencia en diversas áreas peninsulares.

Como dicía, o substantivo cociña (cos seus correlatos cocina e cozinha) está ben documentado nas linguas peninsulares para dar nome a un prato, só que adoita referirse a comidas menos contundentes. O Cândido de Figueiredo documenta, en terras coimbrás, o uso de cozinha para o caldo verde. Rivas Quintas (2001), apud Santamarina (2006), rexistra cociña no Berzo como 'caldo espeso'. A $4^{\mathrm{a}}$ acepción de cocina no DRAE é tamén "caldo (\| líquido que resulta de cocer algunos alimentos)"; non obstante, a acepción anterior xa nos presenta un prato algo máis difícil de dixerir: "Potaje o menestra que se hace de legumbres y semillas, como garbanzos, espinacas, etc.”.

Nas monografías etnolingüísticas aparecen definicións máis xenéricas que se poderían integrar facilmente na definición de Costas. É o caso de Carreiro (1948), que documenta cozinha como "Comida preparada ao lume; cozinhado (constitui o primeiro prato da refeição)” en Nisa (Portalegre), moi preto da fronteira con Cáceres. 
$\S 14$. Sequeiru, niazu: 'alpendre separado ou acaroado á casa onde se garda a palla'

Costas (2013: 189) explica a motivación destas formas: "sequeiru porque tamén é onde secan todo tipo de cereais, niazu é porque entre a palla acostuman a aniñar as galiñas e a parir outros animais".

Non documento en portugués a forma sequeiro para dar nome a un lugar específico onde se garde a palla. Non obstante, está moi ben documentado nos dicionarios e no portugués dialectal (tamén en galego, por certo) con valores moi relacionados, como menciona o propio Costas. En numerosas partes de Portugal, é un dos nomes para o hórreo; tamén dá nome ó "conjunto de tabuleiros onde se seca a fruta" (P.Ed.), ó "lugar onde se estende roupa, artefactos cerâmicos, etc., para enxugar" (Prib.) ou ó "sítio para recolher lenha perto de casa" (CF). Non sorprende, por tanto, que, entre tantos valores relacionados, haxa zonas onde se salte ó significado de 'lugar para recoller a palla'.

Canto á forma niazu, habería que pensar nunha especialización semántica da forma castelá niazo, definida polo DRAE como "almiar (montón de paja)". O dicionario académico etiqueta esta forma como salmantismo, e parece que, desta vez, a marcación diatópica é acaída: en toda a rede do ALCyL (mapa 274) só aparece en tres puntos de Salamanca, precisamente os máis próximos xeograficamente ó Val do Ellas ${ }^{7}$, confirmando o testemuño recollido nesa mesma zona por Iglesias Ovejero (1990). A mesma base está presente en Estremadura, con formas como niara ou nial.

\subsection{Formas sen correspondencia coñecida no portugués ou no castelán veciño}

$\S 15$. Abeleira: 'leiras choídas por muros de pedra' (significado habitual: 'abeledo, árbore que dá abelás')

Non encontro rexistros de aveleira en portugués co significado que se identifica para o Val do Ellas. Si que aparece en ocasións (cf. RL XIX, 178) cun significado dialectal que xa identificara Costas (2013: 188): 'sociedade de dous labradores para o traballo de sementeira, emprestándose mutuamente traballadores, gando e apeiros'.

\section{§16. Choqueira: 'puberdade' (significado habitual: 'lugar onde poñen as galiñas')}

Costas (2013: 188n) sinala (as itálicas son miñas): “os propios falantes dan a definición: «p'aqui se le chama choqueira porque é condo os dagais i as dagalas chocan, tamén le chaman a edai do pavo»". Parece, por tanto, que estamos diante dunha expresión coloquial con motivación humorística, e habería que examinar a vitalidade de ambas as dúas formas e se habería algunha diferenza nos contextos de uso ${ }^{8}$.

Non rexistro nas fontes dialectais consultadas ningún exemplo de uso con este valor, aínda que tampouco é un concepto moi investigado nos estudos de léxico dialectal. Si que existe en portugués o substantivo choquice, que ademais de ser o tempo en que a galiña está choca, tamén ten o significado figurado de 'abatemento' e de 'torpor de ánimo'; de modo

\footnotetext{
${ }^{7}$ Sa500 (Alameda de Gardón), Sa502 (Navasfrías), Sa503 (El Saúgo).

${ }^{8}$ Documento cando menos un rexistro: “¡Pepe!, aquí oíste las primeras palabras de La Fala Lagarteira, aquí té arrullarum las rollas y en cantus e as penhas oivis tu as cançoes en Fala Lagarteira antis é ten us diñus cumu us graniñus de millu antis a Choqueira". http://www.viriato-viera.com/2011/11/huellas-historicas-de-la-sierra-de-gatacaceres/
} 
semellante, choco pode significar 'sen vontade de facer nada, inerte'. Curiosamente, o valor maioritario de choco/a na zona do Sabugal e arredores é outro: 'sucio', cf. Buescu (1961) e Martins (1954).

\$17 Fisgo: 'cavorco, río profundo agochado entre penedos' (significado habitual: 'fenda')

En portugués hai fisga co significado de 'abertura, fenda'. Porén, non documento o sentido de 'río', nin tampouco documento a forma fisgo con ese valor.

§18. Gallofa: 'aloumiño, afago' (significado habitual: 'troula')

O significado habitual no portugués común coincide co galego: 'diversión, escarnio, burla, etc.'; nas fontes dialectais pode ter algún outro valor, por exemplo 'rebanda de pan' en Nisa (Carreiro 1948), posiblemente por castelanismo. Non rexistro o valor semántico que se propón para o Val do Ellas.

§19. Orfandai: 'grupo de rapaces sos, sen acompañamento de adultos' (significado habitual: 'condición de orfo, persoa nova a quen lle morreron os pais')

Non atopei exemplos deste significado nas fontes consultadas. Como acontece con $\S 16$, haberá que pensar nunha creación humorística, verificar cal é o grao real de uso e comprobar se se coñece no Val do Ellas o significado recto ${ }^{9}$.

\subsection{Formas con significados primixenio e derivado moi próximos}

Reúno aquí algunhas designacións que, sempre segundo as informacións de Costas, teñen un significado no Val do Ellas que, ó meu xuízo, é demasiado próximo ó que posúen habitualmente en galego ou portugués como para soster a existencia dunha especialización semántica, como fai o filólogo vigués.

$\S 20$. Achantar: 'caer na lama ou no chan' (significado habitual: 'enterrar, ocultar[se] no chan').

Os significados deste verbo, formado sobre chantar, son moitos e variados, e permiten numerosas evolucións semánticas, como a que dá título a este apartado. O propio Costas (2013: 190) recoñece a proximidade dos significados do galego común e do Val do Ellas:

En galego achantar ten varios significados, sendo os principais 'enterrar, ocultar baixo o nivel do chan ou a nivel do chan e, por extensión de significado achantado, oculto baixo terra, pasa a significar covarde. [...] No Ellas existe con este significante unha deriva parcial cara a caer no chan, pero no chan cheo de lama [...] A terceira acepción do dicionario da RAG é semellante: «Afundirse o carro nun terreo brando ou lamacento de maneira que non poida ser arrastrado polo gando», e no dicionario de Eladio Rodríguez rexístrase unha acepción semellante: «Afundirse un pé, ou as rodas dun carro, na lama», significados ambos os dous directamente emparentados, aínda que non idénticos, coa acepción valega: «caer na lama ou no chan».

\footnotetext{
${ }^{9}$ Parece que si, segundo se deduce deste exemplo: "Cuando algun se há diu deixa un buracu que otro nun poi ocupar i a alma quea un poicu huérfana. I esa orfandai nun se ocupa con suplencias que si ven valin por si mismas, nun tapan as ausencias definitivas". http://www.foro-ciudad.com/usuarios-mensajes.php?IDU=1000540425\&P=7 (consultado o 27 de marzo de 2014).
} 
Non parece, por tanto, que esteamos diante de significados tan afastados como para poder falar dun "significado dialectal valego".

No caso portugués, aínda que existe chantar, prevalecen as formas con metátese (tanchar, atanchar), que aparecen nos dicionarios cun significado máis restrinxido: 'meter unha estaca na terra, asentar unha estaca ou vara, etc.'. Non atopo rexistros das extensións semánticas documentadas no galego e no Val do Ellas.

$\S 21$. Asnal: 'cesto usado na vendima con tiras de castiñeiro' (significado habitual: 'cesto para o estrume ou uva que vai sobre unha besta')

Costas (2013: 190) sinala que asnal está documentado en Trás-os-Montes como "cesto de vime para conduzir estrume em cavalgadura" $(\mathrm{CF})^{10}$ e en falas leonesas arraianas como 'cesto para a vendima que vai aos lombos de burros ou mulas'. A novidade do Val do Ellas radica "[n]o feito de que no Val do Ellas o cesto asnal se use exclusivamente para a vendima, para levar acios de uvas, sen intervención de equinos para o transporte"11. O uso desta forma no Val do Ellas está confirmado por González Salgado (2000), que transcribe asnais no seu punto de enquisa nas Ellas (mapa 175, Vasija en la que se meten los racimos), unha resposta que non aparece no resto da rede.

O matiz semántico que se sinala para o Val do Ellas é pequeno; máis que ó significado, cumpriría acudir á morfoloxía do cesto, para ver ata que punto hai diferenzas co das outras zonas, ou se se tratará esencialmente do mesmo obxecto, co mesmo nome, mais adaptado ás circunstancias particulares da zona.

\section{§22. Babeco: 'chafalleiro, torpe' (significado habitual: 'parvo, idiota').}

A forma habitual no portugués estándar é babão ("que ou quem faz ou diz tolices, ou se revela ingênuo; bobo, palerma, parvo", Houaiss), se ben que as obras lexicográficas tamén conteñen formas máis próximas á documentada no Val do Ellas. En particular, o Houaiss contén unha entrada babeco, marcada como brasileirismo do Paraíba, que se aplica ós habitantes do campo, indicando que son persoas rústicas, sen instrución, ignorantes ou inxenuos. Houaiss, P.Ed. e Prib. inclúen no seu inventario a palabra babaca, marcada tamén como brasileirismo, coa definición "parvo, idiota, tolo" (P.Ed.). Non obstante, CF. documenta a voz babeca "Homem nêscio, basbaque (Cp. babar)", para a que non dá restricións diatópicas, senón que indica que se trata de voz antiga de uso familiar; con todo, non semella unha etiqueta moi acaída, pois Fonseca (1945) recolle aínda babeca na Vermiosa (distrito da Guarda, lindeira coa provincia española de Salamanca) coa definición "homem néscio".

Non encontro nas fontes consultadas ningún exemplo do matiz semántico que se indica para o Val do Ellas. Con todo, salta á vista que, en determinados contextos de uso, pode haber pouca diferenza entre unha situación e outra. Varias definicións falan de "homem néscio", e a primeira acepción de néscio no Porto Editora xa inclúe diferentes matices de descualificación: “que não sabe ou não é muito inteligente; ignorante; estúpido; inepto". É

\footnotetext{
${ }^{10}$ Como outras veces, a etiqueta diatópica do Cândido de Figueiredo non é totalmente rigorosa, xa que os cestos asnais están documentados noutras partes do país, como o Algarve, onde son claramente para o uso con animal, como se aprecia na fotografía de http://radix.cultalg.pt/visualizar.html?id=6141 (consultado o 27 de marzo de 2014)

${ }^{11} \mathrm{E}$ iso fai que Costas poña en discusión o étimo tradicional ASINALE ('de asno', porque o levan os asnos) e propoña unha forma *ACINALE ('de acios', por ser empregue na vendima).
} 
esperable que unha persoa acusada de pouca esperteza non teña tampouco as mellores aptitudes para desenvolver un traballo con rigor e calidade.

\subsection{Outros casos}

\section{§23. Arró, ro: 'algo que está arredor, que cinxe'}

Costas (2013: 191) presenta un amplo abano de significados para esta forma, que inclúe dentro da epígrafe "Exemplos de significante galego con significado dialectal valego": "valado/cadabullo, oureleira/beira, bordo, basta, orla [...] O sentido principal é sempre de algo que está arredor, que cinxe, coma os valados ou os cadabullos rodean ou beirean camiños e campos".

Non obstante, non se entende moi ben cal é o significado innovador con respecto ó galego, xa que arró está ben presente na lexicografía e dialectoloxía galegas, co significado de "talud de tierra, piedras o arbustos que suele servir de linde entre dos fincas" (García 1985). No que respecta a ro, Rey Yelmo (1999) presenta unha entrada mañega ro, que define como "Rodo. Faldón de la camisa", e un significado semellante aparece en Costas (2007), que edita unha escolma de palabras redactada por un informante valverdeiro, que recolleu ro co significado de "bastilla de camisa o camiseta". Este valor tampouco é unha novidade, se ollarmos para a forma rodo, do galego ("Reforzo no contorno dunha peza de roupa", DRAG) e tamén do español; a segunda acepción na entrada do DRAE está marcada, precisamente, como salmantismo, coa definición "Faldón de la camisa, que suele ser de tela más tosca que el resto de la prenda".

Así, os sentidos documentados no Val do Ellas non se afastan do galego e do castelán. Si que o fan, cando menos provisoriamente, do portugués, xa que non encontro trazas de arró nin de ro nas fontes dialectais e lexicográficas portuguesas consultadas.

§24. Boega, boiga: 'Cuarto situado na parte baixa da casa, onde se gardan o viño e os animais' (significado habitual: 'parte da casa onde se garda o viño')

Sinala Costas (2013: 176) que a novidade do Val do Ellas é que "boiga (bodega) non é só almacén onde se garda o viño, é todo cuarto situado na planta baixa, tanto onde se garda o viño coma onde se gardan os animais". Porén, o significado de 'cuarto da planta baixa onde se garda algo' non é ningunha novidade. Non se trata só do significado etimolóxico (latín de orixe grega APOTHĒCA 'almacén'), senón que está ben documentado en galego (p.ex. "parte baja de la casa que sirve de almacén", García 1985; "Parte baixa da casa [...] ou construción adxacente a esta onde se garda e tamén onde se fai o viño e que se usa ás veces como almacén doutras cousas como sementes (sic) ferramentas etc.”, DRAG) ou en castelán. (“6. f. despensa (\| lugar donde se guardan los comestibles). 7. f. troj (\| espacio para guardar cereales). 8. f. En los puertos de mar, pieza o piezas bajas que sirven de almacén a los comerciantes).

No que respecta ó portugués, a forma bodega experimentou, polo xeral, unha deriva semántica cara a valores como 'taberna, casa moi sucia, porcaría'. Non obstante, o seu cognado adega adoita manter o valor que nos ocupa ("parte de uma casa, geralmente subterrânea, 
onde se guarda vinho, azeite e outras provisões", P.Ed.). No portugués fronteirizo, Vilhena (2000) define bodega como "despensa" en Ferreira de Alcántara e Cedillo; en troques, no Sabugal o que se rexistra é o valor xeral no portugués, "porcaría, suciedade'12.

Por tanto, o único matiz que podería reivindicar como propio o Val do Ellas é a aplicación de bodega/boiga ó cuarto dos animais, unha acepción que non atopo nas linguas veciñas. De todas formas, xa advertía Costas (2013: 177) de que o significado por antonomasia é o de 'almacén do viño', mentres que as outras levan especificador (boiga dos cochinos, boiga das ovellas, etc.).

\section{$\$ 25$. Perda da sinonimia entre cacheira e cachola}

Costas (2013: 188) sinala que no Val do Ellas "cacheira e cachola non son sinónimos: unha cacheira é unha pucha para cubrir a cabeza e a cachola é a cabeza do porco ou, humorística ou despectivamente, a cabeza dunha persoa". Isto é, noutras palabras, cacheira perde o significado de 'cabeza de porco' que ten no galego común e adquire un significado próximo metonimicamente.

No entanto, cómpre sinalar que Rey Yelmo (1999) recolle cacheira no seu vocabulario mañego, mais non coa acepción sinalada por Costas (que non documenta), senón definida como "cachiporra hecha con la raíz de un tronco y una vara larga". E, precisamente, é ese un dos significados de cacheira en portugués ("pau tosco; cajado", P.Ed.), que tamén é coñecido nalgunha zona de Galicia, como se documenta no Dicionario de dicionarios editado por Santamarina. En Portugal pode aplicarse tamén a numerosos conceptos do campo semántico dos tecidos e vestidos: "tecido grosseiro de lã; vestimenta feita desse tecido; cobertor grosseiro", uns conceptos próximos ós que se atopan nalgúns dicionarios galegos. Porén, non documento a acepción específica de 'pucho'; habería que coñecer o referente, porque se a dita pucha se confeccionase con teas groseiras, de baixa calidade, entón a identificación sería perfecta.

No que respecta a cachola, a acepción principal na lexicografía portuguesa é, precisamente, 'cabeza', nun rexistro familiar e popular, aínda que tamén pode dar nome ó fígado dos animais (xeralmente, o do porco). As obras portuguesas incluídas no TLPGP suxiren unha distribución xeográfica dos significados, xa que o valor de 'cabeza' está presente na metade norte de Portugal (incluíndo o Sabugal, como testemuña Braga 1971), mentres que é a metade sur a que o usa para o fígado porcino e as súas elaboracións culinarias, excepto en Braganza, onde designa as moelas.

En definitiva, tamén se perde a correspondencia entre cachola e cacheira no dominio portugués. Cachola segue significando 'cabeza' en portugués e no Val do Ellas, mentres que cacheira pode ter nesta última variedade dous significados, o que rexistra Rey Yelmo, con correspondencia perfecta en portugués e nalgunhas localidades galegas, e mais o que indica Costas, para o campo semántico dos tecidos e vestidos, onde tamén se coñece cacheira en portugués e galego, só que sen unha correspondencia plena de significados.

\footnotetext{
${ }^{12}$ http://capeiaarraiana.pt/2012/09/29/o-falar-de-riba-coa-o-lexico-18/ (consultado o 10 de marzo de 2014)
} 
§26. Chouriceiro: 'paporroibo, Erithacus rubecula' (significado habitual: 'persoa que fai chourizos')

Esta designación hai que entendela como unha metáfora. A característica cor do peito do paxaro pode interpretarse como unha mancha que lle quedou despois de comer un chourizo (ou de facelo), ou pode ser tamén unha comparación co embutido pola semellanza cromática, sen necesidade de acción por parte do paporroibo no imaxinario popular. As comparacións con alimentos e bebidas non son estrañas nas designacións deste animal; a descrición panorámica do Atlas Linguistique Roman infórmanos (Caprini 2009: 451-452) da existencia das designacións vinagreira no portugués azoriano e pimentón e pimentero no castelán occidental, con continuidade en Portugal; o ALEPG recupera en Salvaterra do Extremo (distrito de Castelo Branco, a uns $40 \mathrm{~km}$ do val do Ellas) a forma pimenteiro, e pimento máis para o interior, en Sabugueiro, distrito da Guarda.

Non considero que se poida clasificar esta designación dentro do caso de "significante galego con significado dialectal valego" (Costas 2013: 188). Trátase dun proceso ben diferente ó que se dá noutras formas analizadas neste traballo; non estamos diante dunha deriva semántica ou dun proceso de especialización, senón que hai un uso metafórico que non anula o significado primario nin provén dunha evolución a partir do semantismo primixenio. De feito, Rey Yelmo (1999) documenta no mañego a forma chuiriceiro, no seu significado recto de 'persoa que fai chourizos', sen sinalar outras acepcións; tamén se rexistra no concello das Ellas como o lugar no que se poñen os chourizos e outros enchi$\operatorname{dos}^{13}$.

§27. Colar: 'colar [para animais]' (significado habitual: 'colar [para persoas ou animais]')

No portugués estándar, o colar refírese apenas a persoas. Non obstante, no portugués dialectal tamén se pode empregar como sinónimo de coleira, isto é, a tira de coiro que se pon ó pescozo dalgúns animais da que prenden os chocallos.

Isto é, precisamente, o que acontece no portugués máis próximo ó val do Ellas. Tanto Braga (1971) coma Buescu (1961), Fernandes (1965) e Maia (1977) documentan colar para animais do lado portugués da Raia; en Cedillo e Ferreira de Alcántara tamén se rexistra, como demostra Vilhena (2000). Por último, unha consulta á base de datos do ALEPG deixa ver que os rexistros de colar nos distritos de Castelo Branco (Rosmaninhal e Isna) e Guarda (Vale da Mula e Foios) refírense apenas ós animais, mentres que máis para o interior, en Viseu, xa aparece co significado de 'parte da camisa'.

Observamos, por tanto, unha clara continuidade entre o portugués beirón e o Val do Ellas; sempre, por suposto, segundo as fontes consultadas, pois aínda que non existan rexistros do uso de colar para persoas, e si abundantes probas da aplicación a animais, non se pode afirmar que o primeiro non exista.

\section{Conclusións}

Neste traballo analizáronse 27 designacións que Costas (2013: 188) presentara como posuidoras dun "significado dialectal valego", diferente do uso normal no galego. A intención

\footnotetext{
${ }^{13}$ Churiceiru, en http://mais.vieiros.com/letras2002/libro.pdf (p. 170).
} 
deste artigo foi verificar, dun modo sistemático, se eses significados particulares estaban presentes nas variedades lingüísticas veciñas ó Val do Ellas, especialmente no portugués, para poder corroborar ou refutar esa afirmación, un dos argumentos empregados para soster un illamento da fala dos Tres Lugares con respecto ás linguas veciñas e, máis especificamente, para afastar esas variedades do portugués dialectal, postura que vai en beneficio da tese dunha filiación galega.

Case a metade (12) das designacións examinadas mostraron unha clara continuidade semántica co portugués de Portugal (sección 3.1.) ou co portugués falado nas comunidades lusófonas do lado español da fronteira (sección 3.2.); ademais, outras 2 denominacións non se rexistraron en español ou portugués cun significado idéntico ó do Val do Ellas, mais si moi próximo (sección 3.3.). Por contra, apenas 5 das designacións presentadas por Costas como semantismos orixinais (o $18,5 \%$ ) teñen un significado particular que se afasta claramente das linguas veciñas, e aínda así, habería que analizar o grao de uso dalgunha delas. Por último, as seccións 3.5. e 3.6. reuniron casos problemáticos de diferente tipo que fixeron máis prudente non adscribilas taxativamente a algunha categoría; neses dous apartados hai formas con significados equivalentes en portugués e outras que, a priori, están ausentes desa lingua.

Cómpre mencionar que, en varios casos, detectouse tamén que o suposto cambio de significado do Val do Ellas con respecto ó galego non era tal, xa que as fontes dialectais documentaban en Galicia o mesmo valor que se rexistraba nos Tres Lugares. Non é estraño. Os significados existentes na lingua, hoxe e en épocas pretéritas, son sempre máis variados do que se recolle nos dicionarios; incluso obras dialectais de perspectiva ampla, como os atlas lingüísticos, deixan escapar algunhas designacións que nos recuperan as obras con foco microdialectal. Acontece así con: §6. Liña: 'fío para coser'; §7. Mela, melar, melao: 'Corte, necha, nicada ou fanada que ten ou se lle fai a un obxecto'; §8. Vieiro: 'gabia, escavación lineal realizada polo home' (significado común: camiño estreito); §9. Xaneiro/a: 'Primeira cría nacida no ano e as crías ou froitos que veñen en xaneiro' (significado común: 'primeiro mes do ano'); §23. Arró/ro: 'Algo que está arredor, que cinxe'.

Como conclusión global, semella difícil soster que no Val do Ellas exista un grao de es-

pecialización semántica relevante con respecto ó galego ou ó portugués. É evidente que as palabras estudadas neste traballo conforman un corpus reducido, mais tamén é certo que se trata dun corpus escollido ex profeso polo seu compilador, peneirando o vocabulario de Xálima de formas claramente coincidentes con outras variedades; por tanto, un exame de entradas lexicais aleatorias ou unha análise da totalidade de recollas sistemáticas dificilmente mostraría máis diferenzas entre esas falas cacereñas e outras variedades galegoportuguesas.

Por último, ponse de manifesto a esixencia ineludible de que os estudos lingüísticos sobre o Val do Ellas tomen en consideración as fontes dialectais portuguesas (ademais, claro está, das astur-leonesas e castelás). Só deste modo se conseguirá unha imaxe realista da situación lingüística e se poderán facer afirmacións sólidas sobre a identidade lingüística da zona e sobre a tan debatida questione da filiación lingüística.

\section{Bibliografía}

Alvar, Manuel (1999): Atlas lingüístico de Castilla y León (3 vols.). Valladolid: Junta de Castilla y León, Consejería de Educación y Cultura. 
BAPTISTA, Cândida da Saudade Costa (1967): O falar da Escusa. Tese de licenciatura inédita. Lisboa: Universidade de Lisboa.

BRAGA, Franklim Costa (1971): Quadrazais. Etnografia e Linguagem. Tese de licenciatura inédita. Lisboa: Universidade de Lisboa.

BuesCu, Maria Leonor Carvalhão (1961): Monsanto. Etnografia e linguagem. Lisboa: Centro de Estudos Filológicos.

CARRAsco GonzÁlez, Juan Manuel (1996): "Hablas y dialectos portugueses o galaicoportugueses en Extremadura. (Parte I: Grupos dialectales. Clasificación de las hablas de Jálama)". Anuario de Estudios Filológicos XIX: 135-148. $<$ http://dialnet.unirioja.es/descarga/articulo/58870.pdf $>$

CARré Alvarellos, Leandro $\left(1951^{3}\right)$ : Diccionario galego-castelán. A Coruña: Roel.

CARREIRO, Maria Eduarda Ventura (1948): Monografia linguística de Nisa. Tese de licenciatura inédita. Lisboa: Universidade de Lisboa.

Carvalho, Maria Armanda da Cunha Albino (1970): Sátão (Concelho do distrito de Viseu). Estudo da linguagem, etnografia e folclore das suas freguesias. Tese de licenciatura inédita. Coimbra: Universidade de Coimbra.

Costas GonzÁlez, Xosé Henrique (2001): "Fronteiras lingüísticas no Val do Río Ellas (Cáceres)”. Revista de Filología Románica 18: 35-50.

http://revistas.ucm.es/index.php/RFRM/article/view/RFRM0101120035A

Costas GonzÁlez, Xosé Henrique (2005): “Achegas ao léxico do galego falado no Val do Río Ellas”. Cadernos de Lingua 27: 127-153.

Costas GonzÁlez, Xosé Henrique (2007): “Os apañadores de palabras: o caderno do pastor, labrego e escultor valverdeiro Alfonso Berrío". A Trabe de Ouro 70:115-133.

Costas GonzÁlez, Xosé Henrique (2013): O valego. As falas de orixe galega do Val do Ellas (Cáceres-Estremadura). Vigo: Xerais.

Cummins, John G. (1974): El Habla de Coria y sus cercanías. London: Tamesis Books

FERNANDES, João Baptista (1965): Linguagem de Aldeia Velha e povoações vizinhas. Tese de licenciatura inédita. Coimbra: Universidade de Coimbra.

FonseCA, Delfina Maia da (1945): Subsídios para o estudo da linguagem popular da Vermiosa. Tese de licenciatura inédita. Lisboa: Universidade de Lisboa.

GARcíA, Constantino (1985): Glosario de voces galegas de hoxe. Santiago de Compostela: Universidade de Santiago de Compostela [Anexo 27 de Verba. Anuario galego de Filoloxía]

GARcía ARES, Maricarmen (2000): Nuevo suplemento al Diccionario gallego-castellano, publicado en 1884 por D. Marcial Valladares Núñez [1893-1896]: Edición e estudio. A Coruña: Real Academia Galega [Anexo 4 de Cadernos de lingua].

GARGALLO, José Enrique (2007): “Gallego-portugués, iberorromance. La 'fala' en su contexto románico peninsular". Limite: Revista de Estudios Portugueses y de la Lusofonía 1: 31-49. < http://www.revistalimite.es/volumen\%201/EnriqueGargallo.pdf>

GonZÁlez SAlGADO, José Antonio (2000): Cartografía lingüística de Extremadura. Origen y distribución del léxico extremeño. Tese de doutoramento. Madrid: Universidade Complutense. http://www.geolectos.com

IgLESIAS OvEJERO, Ángel (1990): El habla de El Rebollar (Salamanca): Léxico. Salamanca: Centro de Cultura Tradicional, Diputación de Salamanca. 
MAIA, Clarinda de Azevedo (1977): Os falares fronteiriços do concelho do Sabugal e da vizinha região de Xalma e Alamedilla. Coimbra: Universidade de Coimbra [Separata da Revista Portuguesa de Filologia, IV]

MARTINS, José Dias (1954): Etnografia, linguagem e folclore de uma pequena região da Beira Baixa (Póvoa de Atalaia, Alcongosta, Tinhalhas e Sobral do Campo). Tese de licenciatura inédita. Lisboa: Universidade de Lisboa.

ReInAS, Maria Augusta da Fonseca Monteiro (1957): Nave de Haver e Alamedilla: etnografia, língua e folclore de duas aldeias arraianas (2 vols.). Tese de licenciatura inédita. Lisboa: Universidade de Lisboa.

ReY Yelmo, Jesús C. (1999): La fala de San Martín de Trevejo: O mañegu. Notas y vocabulario. Mérida: Editora Regional de Extremadura.

RIVAS QUINTAS, Eligio (1978): Frampas: contribución al diccionario gallego. Salamanca: Ceme.

RODRÍGUEZ GONZÁLEZ, Eladio (1958-1961): Diccionario enciclopédico gallego-castellano. Galaxia: Vigo.

SAntAmarina, Antón (ed.) (2006-): Dicionario de dicionarios da lingua galega. $<$ http://sli.uvigo.es/DdD/index.html $>$.

VILHENA, Maria da Conceição (2000): Falares de Herrera e Cedillo. Mérida: Editora. 